\title{
RELAÇÕES SOCIAIS NO MEIO RURAL NA ERA DA INFORMAÇÃO: UM ESTUDO NA COMUNIDADE RURAL DE VILA TIGRE - XAXIM/SC
}

\author{
Andressa Sanssanoviez 1 \\ Marcos Junior Marini² \\ Miguel Ângelo Perondi ${ }^{3}$
}

\begin{abstract}
RESUMO
Estudos demonstram que nos últimos anos as Tecnologias de Informação e Comunicação (TICs) estão transformando o mundo em diversos aspectos, principalmente hábitos e costumes. Essas tecnologias permitem a interação em rede e a construção compartilhada do saber em uma velocidade nunca antes vista. O objetivo deste artigo é compreender se as TICs fortalecem ou tornam frágeis as relações sociais, incluindo a confiança, solidariedade e cooperação no meio rural. Este estudo foi realizado na comunidade de Vila Tigre, localizada no município de Xaxim/SC. A coleta de dados ocorreu através de entrevista semiestruturada, realizada com representantes de grupos sociais existentes no local. O estudo demonstrou que as Tecnologias de Informação e Comunicação estão influenciando de múltiplas maneiras as relações sociais na comunidade pesquisada, sendo que, ao mesmo tempo em que oferecem possibilidades de comunicação, troca de informações e agilidade, também causam afastamento e desconfiança.
\end{abstract}

Palavras-chave: Tecnologias de Informação e Comunicação, TICs, relações sociais, rural.

\section{RURAL SOCIAL RELATIONSHIPS IN THE INFORMATION AGE: A STUDY IN THE VILA TIGRE RURAL COMMUNITY - XAXIM/SC}

\begin{abstract}
Studies show that in recent years Information and Communication Technologies (ICTs) are transforming the world in many aspects, especially habits and customs. These technologies enable networking and shared construction of knowledge at a speed never seen before. The purpose of this paper is to understand if ICTs strengthen or weaken social relations, including trust, solidarity and cooperation in rural areas. This study was conducted in the community of Vila Tigre, located in the

\footnotetext{
${ }^{1}$ Graduada em Comunicação Social - Habilitação em Jornalismo (CELER FACULDADES). Mestranda no Programa de Pós-Graduação em Desenvolvimento Regional (PPGDR) da Universidade Tecnológica Federal do Paraná (UTFPR). E-mail: andressajornalista27@gmail.com

2 Graduado em Processamento de Dados (UTFPR). Mestrado em Informática (UFPR). Doutorado em Tecnologia (UTFPR). Professor do Programa de Pós-Graduação em Desenvolvimento Regional (PPGDR) da Universidade Tecnológica Federal do Paraná (UTFPR). E-mail: marini@utfpr.edu.br

3 Graduado em Agronomia (UFPR). Mestrado em Administração (UFLA). Doutorado em Desenvolvimento Rural (UFRGS). Professor do Programa de Pós-Graduação em Desenvolvimento Regional (PPGDR) da Universidade Tecnológica Federal do Paraná (UTFPR). E-mail: perondi@utfpr.edu.br
} 
municipality of Xaxim/SC. Data collection occurred through semi-structured interviews conducted with representatives of social groups in the place. The study showed that Information and Communication Technologies are influencing social relations in the researched community in multiple ways, while at the same time offering possibilities for communication, information exchange and agility, they also cause withdrawal and distrust.

Keywords: Information and Communication Technologies, ICTs, social relations, rural.

\section{INTRODUÇÃO}

Ainda hoje, as áreas rurais são lembradas pelas relações de reciprocidade, solidariedade e cooperação, principalmente durante festas e eventos promovidos pelas comunidades. Essas relações sólidas entre vizinhos e amigos são herança de antepassados que tinham nos mutirões de trabalho, troca de alimentos, empréstimo de equipamentos, laços de confiança e reciprocidade.

Em estudo, Putnam (1996) verificou que regiões mais cívicas, ou seja, com níveis elevados de cooperação, reciprocidade, confiança, são, geralmente, as mais prósperas. Adicionalmente, o autor considera que o sucesso dos territórios está relacionado a reciprocidade e a participação, sendo que essas relações facilitam a troca de informações sobre vários aspectos e inibe o oportunismo.

A importância das relações sociais está inserida no sucesso dos territórios. Nesse sentido, pode-se aplicar o conceito de "embeddedness" (imersão), tratado incialmente por Karl Polanyi e ampliado por Granovetter (2007), o qual afirma que as pessoas não agem nem tomam decisões fora de um contexto social, em vez disso, as ações estão profundamente imersas, enraizadas nas redes de relações sociais. Amaral Filho (2001) corrobora afirmando que os territórios se constituem de um conjunto econômico e social, em que ocorre a interação e a troca de saberes, sendo que nesse espaço se processam a aprendizagem coletiva e o desenvolvimento de novos conhecimentos. Para Abramovay (2000), as relações sociais estão imbricadas no processo de desenvolvimento de um espaço, sendo que este, necessita de um ambiente de cooperação entre os atores para a valorização dos atributos de determinada região. Adicionalmente, o mesmo autor considera importante que sejam desenvolvidas inciativas nos próprios territórios para a formação de redes territoriais de desenvolvimento.

A partir deste contexto, a necessidade de formação de redes entre os atores tem as Tecnologias de Informação e Comunicação (TICs) como mediadoras deste processo. Na era da informação, as tecnologias desempenham um papel importante na troca de informações e conhecimentos entre os diferentes atores e territórios, ultrapassando as barreiras de espaço e tempo. Albagli (2004) considera que as redes técnicas, como por exemplo e teleinformática, auxiliam na integração de territórios, facilitam a troca de informações, bens e capital.

O termo Tecnologias de Informação e Comunicação (TICs) é polissêmico, carecendo de alguns esclarecimentos preliminares em termos do alinhamento construído para o presente artigo. Nesse sentido, parte-se da proposição apontada por Conceição (2012, p. 15) em que as "TICs incluem todos os recursos tecnológicos integrados, como rádio, televisão, computador, que geram

conhecimento, informação e comunicação interferindo nos processos informacionais." 
A partir deste contexto, o objetivo deste estudo é compreender a influência das TICs nas relações sociais. Logo, pretende-se verificar se essas tecnologias fortalecem ou tornam frágeis os laços de confiança, solidariedade e cooperação no meio rural. Este estudo foi realizado na comunidade de Vila Tigre, localizada no município de Xaxim, região Oeste do Estado de Santa Catarina.

Assim, apresentar-se-á na próxima seção a metodologia utilizada para o desenvolvimento desta pesquisa. A seguir, abordar-se-á sobre a importância de elementos como confiança e reciprocidade nas relações sociais e a força dos laços, bem como a inserção das TICs nas relações sociais. E, por fim, serão apresentados os resultados desta pesquisa de campo.

\section{METODOLOGIA}

De acordo com os dados do Censo Demográfico 2010, a população do município de Xaxim está estimada em 25.713 pessoas, sendo 20.967 urbana e 4.746 rural. A economia do meio rural do município está baseada na produção de grãos (milho, soja, feijão), produção de leite, aves e suínos. Ainda, os dados do Censo Agropecuário de 2006, divulgados pelo Instituto Brasileiro de Geografia e Estatística, em Xaxim/SC, 249 estabelecimentos rurais (19\%) não são considerados de agricultura familiar, enquanto 1045 (81\%) são caracterizados como unidades de agricultura familiar. Nesta perspectiva, visualiza-se a predominância da agricultura familiar no município estudado.

A comunidade de Vila Tigre está localizada a cerca de $10 \mathrm{~km}$ do centro da cidade de Xaxim/SC. O local é considerado referência, pois dispõe de uma escola de nível fundamental, posto de atendimento de saúde (atualmente desativado), unidade de uma cooperativa agroindustrial e o centro comunitário de Vila Tigre. No local são realizados diversos eventos no decorrer do ano, sendo eles: religiosos (romaria), jantar italiano do clube de mães, jantar da comunidade, eventos do clube esportivo, de idosos e escolares. Além de outras festividades de caráter particular.

Este estudo adotou a abordagem qualitativa e quantitativa, de forma complementar, pois conforme Minayo (2009, p. 22), "entre eles há uma oposição complementar que, quando bem trabalhada teórica e praticamente, produz riqueza de informações, aprofundamento e maior fidedignidade interpretativa". Essa combinação oferece mais credibilidade e validade aos resultados da pesquisa, evitando-se o reducionismo por apenas um tipo de análise. "[...] Fazer pesquisa não é acumular dados e quantificá-los, mas analisar causas e efeitos, contextualizandoos no tempo e no espaço, dentro de uma concepção sistêmica" (OLIVEIRA, 2012, p. $39-40)$. Nesta perspectiva, Richardson (2015, p. 89) corrobora no sentido de que a pesquisa social deve estar voltada para a melhoria das condições de vida das pessoas, "portanto, é necessário, na medida do possível, integrar pontos de vista, métodos e técnicas para enfrentar esse desafio".

O procedimento utilizado para a coleta de dados foi a entrevista semiestruturada. Minayo (2009) considera a entrevista uma conversa entre dois, ou vários interlocutores, que tem por objetivo obter informações importantes para a pesquisa ou objeto estudado. Destaca-se que a entrevista semiestruturada combina perguntas fechadas e abertas em que o entrevistado pode discorrer. Gil (2010) define a entrevista como uma forma de diálogo e interação social. Ressalta-se que as entrevistas foram gravadas e posteriormente transcritas.

Para a seleção dos respondentes foram incluídos na pesquisa atores que durante o período das entrevistas coordenavam entidades/grupos existentes na comunidade de Vila Tigre, Xaxim/SC. A partir desse pressuposto, foram entrevistados cinco representantes, sendo um de cada instituição: clube de mães, 
grupo de idosos, clube esportivo, coordenador do conselho da comunidade e o gerente de uma cooperativa localizada na comunidade. As entrevistas foram realizadas durante o mês de julho de 2018 na residência dos atores entrevistados.

No que tange as perguntas que basearam este artigo, estas estão relacionadas às práticas de cooperação que acontecem na comunidade, sobre a solidariedade e a confiança, se estes são elementos visíveis e praticados na comunidade, e a importância desse tipo de ação. Além disso, questionou-se acerca das Tecnologias de Informação e Comunicação, se estas interferem nas relações sociais e de que forma. Esses questionamentos nortearam as entrevistas e serão discutidos na apresentação dos resultados.

\section{SOLIDARIEDADE, RECIPROCIDADE E CONFIANÇA NAS RELAÇÕES SOCIAIS NA ERA DA INFORMAÇÃO}

O desenvolvimento de Tecnologias de Informação e Comunicação, por meio de redes de computadores e telefonia, está mudando o modo de relacionamento social, questões culturais e, portanto, o mundo rural. Thornton (2003) considera que essas tecnologias permitem que as pessoas estejam em todos os lugares e em tempo real, ultrapassando as barreiras de espaço e tempo. A medida em que ocorre a inserção dessas tecnologias no meio rural, uma nova configuração da rotina se estabelece, gerando novas formas de aquisição de informações e relação entre os atores (FELIPPI; DEPONTI; DORNELLES, 2017).

A sociedade da informação gera inúmeras transformações, apesar disso, elementos como confiança, reciprocidade, associativismo são elementos importantes nas relações sociais, e continuam sendo fundamentais no contexto de uma comunidade. Em estudo, Putnam (1996) percebeu que a confiança promove a cooperação. Ou seja, esse elemento é ingrediente importante em uma comunidade, pois quanto mais elevado o grau de confiança, maior a probabilidade de cooperação. Além disso, a própria cooperação gera confiança.

Para ilustrar a importância da cooperação e confiança para o bem comum, Putnam (1996, p. 173) cita David Hume, que conta uma parábola.

\footnotetext{
“Teu milho está maduro hoje; o meu estará amanhã. É vantajoso para nós dois que eu te ajude a colhê-lo hoje e que tu me ajudes amanhã. Não tenho amizade por ti e sei que também não tens por mim. Portanto não farei nenhum esforço em teu favor; e sei que se eu te ajudar, esperando alguma retribuição, certamente me decepcionarei, pois não poderei contar com a tua gratidão. Então, deixo de ajudar-te; e tu me pagas na mesma moeda. As estações mudam; e nós dois perdemos nossas colheitas por falta de confiança mútua."
}

Portanto, observa-se que quando não existe confiança, ambas as partes podem ter prejuízos e perder oportunidades de proveito mútuo. Nesta perspectiva, em uma comunidade onde existe reciprocidade, participação, confiança, aumenta a eficiência da sociedade e facilita as ações coordenadas. Em uma comunidade rural, como a deste estudo por exemplo, onde um agricultor ajuda o outro e os implementos são reciprocamente emprestados, permite que cada agricultor realize suas atividades com menos equipamentos, favorecendo ambos os agricultores (PUTNAM, 1996). 
De acordo com Polanyi (1980, p. 65), "a descoberta mais importante nas recentes pesquisas históricas e antropológicas é que a economia do homem, como regra, está submersa em suas relações sociais". Ou seja, o indivíduo age em prol de sua situação ou exigência social.

[...] a manutenção dos laços sociais é crucial. Primeiro porque, infringindo o código estabelecido de honra ou generosidade, o indivíduo se afasta da comunidade e se torna um marginal; segundo porque, a longo prazo, todas as obrigações sociais são recíprocas, e seu cumprimento serve melhor aos interesses individuais de dar-e-receber. Essa situação deve exercer uma pressão contínua sobre o indivíduo no sentido de eliminar do seu consciente $o$ auto interesse econômico, a ponto de torná-lo incapaz, em muitos casos (mas certamente não em todos), de compreender até mesmo as implicações de suas próprias ações em termos de um tal interesse. Essa atitude é reforçada pela frequência das atividades comunais, tais como partilhar do alimento na caça comum ou participar dos resultados de alguma distante e perigosa expedição tribal. O prêmio estipulado para a generosidade é tão importante, quando medido em termos de prestígio social, que não compensa ter outro comportamento senão o de esquecimento próprio (POLANYI, 1980, p. 66).

Neste contexto, nas comunidades em que a reciprocidade ${ }^{4}$ é obedecida, os problemas de ação coletiva são mais facilmente resolvidos, o que dificulta o oportunismo.

As regras de reciprocidade generalizada e os sistemas de participação cívica estimulam a cooperação e a confiança social porque reduzem os incentivos a transgredir, diminuem a incerteza e fornecem modelos para a cooperação futura (PUTNAM, 1996, p. 186).

Nesta perspectiva, quando a confiança é retribuída, existe maior probabilidade de existir intercâmbio, o que incentiva uma reciprocidade generalizada ao longo do tempo. O indivíduo sente-se no dever de retribuir o que lhe foi feito. Para Putnam (1996, p. 182-183), "a boa regra da reciprocidade generalizada em geral está associada a um amplo sistema de intercâmbio social". Adicionalmente, o mesmo autor afirma que a confiança, participação, tendem a ser cumulativas, da mesma forma que a desconfiança, omissão. Nas comunidades cívicas "os círculos virtuosos redundam em equilíbrios sociais com elevados níveis de cooperação, confiança, reciprocidade, civismo e bem-estar coletivo" (PUTNAM, 1996, p. 186). Já a inexistência desses elementos em comunidades não cívicas tende a reforçar-se. A desconfiança, a omissão, o isolamento e a desordem criam círculos viciosos.

As relações pessoais podem evitar a má-fé e o oportunismo, pois nessas relações reside a confiança, que por sua vez, desencoraja a má-fé. Granovetter

\footnotetext{
${ }^{4}$ Conforme Putnam (1996, p. 181), existem dois tipos de reciprocidade; "balanceada" (ou específica) e reciprocidade "generalizada" (ou difusa). A reciprocidade balanceada é quando acontece a troca de itens de igual valor; o autor cita o exemplo de dias de folga ou quando políticos combinam de apoiar-se. Por sua vez, a reciprocidade generalizada ocorre quando apresenta um desequilíbrio, ou seja, existe a expectativa que um favor oferecido hoje seja retribuído futuramente. A amizade é um exemplo de reciprocidade generalizada.
} 
(2007) considera que as relações sociais são as principais responsáveis pela produção de confiança e honestidade, no entanto, podem ser usadas como recursos para a má-fé. A confiança originada nas relações pessoais pode tornar-se uma oportunidade para o oportunismo, pois quanto maior a confiança, maior a possibilidade de má-fé. O mesmo autor afirma que para compreender a força dos laços nas relações interpessoais é necessário observar a quantidade de tempo, intimidade entre as partes, confiança mútua, intensidade emocional e as ações recíprocas. Essas características são importantes para definir a natureza dos laços, que podem ser fortes ou fracos.

Os laços fortes podem ser definidos pela maior intensidade das relações; como laços familiares, de amizade ou pequenos círculos. Já os laços fracos são caracterizados pela baixa intensidade de confiança mútua e menos reciprocidade nas relações; são colegas de trabalho, conhecidos. Quanto menos contatos um indivíduo tiver, mais ele fica fechado em termos de conhecimento, informações, ideias em seu próprio círculo de amizade. Neste aspecto, os laços fracos são fundamentais para que o indivíduo receba informações de fora de seu círculo habitual (GRANOVETTER, 1973).

O campo de estudo deste artigo evidencia a presença de laços fortes e fracos entre os atores entrevistados. Ao mesmo tempo em que se estabelecem relações mais intensas entre familiares e a própria comunidade, as TICs oferecem a possibilidade de conexões mais frágeis, que também apresentam-se como importantes para as relações socais.

Os primeiros anos do Século XXI correspondem a um período de transformações, marcado principalmente pela utilização das novas Tecnologias da Informação e Comunicação (TICs). As novas TICs possibilitaram uma transformação no modo como as pessoas se comunicam umas com as outras (ANDRADE; SANTOS, 2015).

Diante das mudanças geradas pela Era da Informação, inclusive no que tange as relações sociais, cabe o questionamento: que futuro nos aguarda? Segundo Schaff (1993, p. 15), "todas as pessoas pensantes do mundo percebem que nos encontramos diante de uma mudança profunda, que não é apenas tecnológica, mas abrange todas as esferas da vida social". A década de 1990 sinalizou a chegada da Sociedade da Informação e do Conhecimento, que difundiu as Tecnologias de Informação e Comunicação. No campo das TICs, o advento e disseminação da internet foram o marco de uma nova era, onde não existem mais barreiras de identidade, espaço e tempo (VIERO; SILVEIRA, 2011).

Neste contexto, as tecnologias tornaram possível a integração de formas de comunicação em uma rede interativa. O novo sistema de comunicação transforma o espaço e tempo, localidades integram-se em redes e se desprendem do sentido cultural e histórico do qual fazem parte. Castells (2010) salienta que, por conta da dimensão global, o novo sistema de comunicação está mudando e mudará para sempre nossa cultura.

A integração potencial de texto, imagens e sons no mesmo sistema - interagindo a partir de pontos múltiplos, no tempo escolhido (real ou atrasado) em uma rede global, em condições de acesso aberto e de preço acessível muda de forma fundamental o caráter da comunicação. E a comunicação, decididamente, molda a cultura porque, como afirma Postmam "nós não vemos...a realidade... como 'ela' é, mas como são nossas linguagens. E nossas linguagens são nossos meios de comunicação. Nossos meios de comunicação são nossas metáforas. Nossas metáforas criam o conteúdo de nossa 
cultura". Como a cultura é mediada e determinada pela comunicação, as próprias culturas, isto é, nossos sistemas de crenças e códigos historicamente produzidos são transformados de maneira fundamental pelo novo sistema tecnológico e o serão ainda mais com o passar do tempo (CASTELLS, 2010, p. 414).

Assim, a Rede 5 é apropriada para a formação de múltiplos laços fracos, os quais são importantes para a troca de informações. "A vantagem da Rede é que ela permite a criação de laços fracos com desconhecidos, num modelo igualitário de interação [...] (CASTELLS, 2010, p. 445)". Os laços fracos, tanto on-line quanto offline, auxiliam no contato entre as pessoas, ampliando a sociabilidade. Adicionalmente, o mesmo autor considera que a Internet auxilia na expansão das relações sociais e amplia sua discussão afirmando que as comunidades virtuais são mais fortes do que muitos observadores pensavam, sendo que as redes sociais interpessoais, baseadas em laços fracos, também são capazes de produzir reciprocidade.

No meio rural as Tecnologias de Informação e Comunicação facilitaram o acesso à informação e conhecimento. Conforme Viero e Silveira (2011), a propagação das TICs, principalmente a internet, tornou necessária a adaptação dos agricultores, que cada vez mais precisam de informações atualizadas para gerir a propriedade. Blanco Romero e Cànoves Valiente (2005) corroboram afirmando que uma forte comunicação endógena, consolidada em um território, é possível favorecer a comunicação exógena, ou seja, a internet pode ser considerada um meio de reconhecimento das diferenças espaciais. Além disso, o equilíbrio territorial e a descentralização são algumas das várias virtudes das TICs a serviço dos territórios, sendo que a sociedade informacional e o desenvolvimento local devem estar inevitavelmente unidos.

\section{ANÁLISE DOS RESULTADOS E DISCUSSÕES}

Embora considerada importante para o desenvolvimento de áreas rurais, bem como um dos elemento das relações sociais na contemporaneidade, a internet ainda é pouco acessível. Conforme os dados do Censo Agropecuário 2017, os quais foram divulgados pelo Instituto Brasileiro de Geografia e Estatística (IBGE), o acesso à Internet cresceu $1.790,1 \%$ desde 2006. Em 2017, 1.425.323 produtores declararam ter acesso à Internet, enquanto em 2006, eram apenas 75 mil. Observase que o acesso à internet ainda é restrito no meio rural brasileiro, considerando que $72 \%$ dos estabelecimentos agropecuários não possuem acesso à internet.

De acordo com Santos (2003, p. 3), a internet é uma infovia de mão dupla, sendo que a falta de acesso retira das pessoas a possibilidade de inserir na rede o padrão cultural de sua realidade local. "Portanto, incluir digitalmente é facilitar o acesso dos excluídos ao novo modo de produção e estilo de desenvolvimento social e cultural".

Ao mesmo tempo em que a internet surge como uma tecnologia para a inserção das pessoas na dinâmica global, as mídias eletrônicas se incorporam nas relações sociais e constroem novas redes sociais e novos comportamentos. Diante do exposto, com o intuito de compreender a influência das Tecnologias de

\footnotetext{
${ }^{5}$ De acordo com Castells (2010, p. 566), "Rede é um conjunto de nós interconectados. Nó é o ponto no qual uma curva se entrecorta. [...] Redes são estruturas abertas capazes de expandir de forma ilimitada, integrando novos nós desde que consigam comunicar-se dentro da rede, ou seja, desde que compartilhem os mesmos códigos de comunicação (por exemplo, valores ou objetivos de desempenho).
} 
Informação e Comunicação nas relações de confiança, solidariedade, cooperação no meio rural, foi realizado um estudo na comunidade rural de Vila Tigre, localizada no município de Xaxim/SC.

A partir do relato dos entrevistados, evidenciou-se que a comunidade realiza várias práticas de cooperação. Entre algumas famílias ocorre a troca de equipamentos, ou horas de trabalho e outros agricultores compram equipamentos em conjunto. Os mutirões ocorrem principalmente durante as festividades da comunidade, para organizar o espaço, fazer a limpeza da igreja, pavilhões entre outras atividades. Em todos os eventos promovidos pela comunidade ocorre cooperação, disse um dos entrevistados.

"A celebração é uma cooperação, ministros, toda liderança é uma cooperação, porque ninguém recebe, é feito gratuitamente. Se não tivesse isso nenhuma comunidade existiria (Entrevistado 1)".

Essa perspectiva está associada ao discurso de Putnam (1996), em que afirma que em uma comunidade onde existe reciprocidade, participação, confiança, aumenta a eficiência da sociedade e facilita as ações coordenadas. Adicionalmente, o entrevistado 2 ressaltou a importância da cooperação para a permanência das comunidades.

"Se não tem essa cooperação, a comunidade vai para trás. $A$ gente vê as comunidades onde não tem esse entrosamento, cada dia está diminuindo mais (Entrevistado 2)".

A partir do excerto apresentado evidencia-se a necessidade de elementos relacionados a confiança, cooperação e solidariedade entre os atores de uma comunidade. Quando esses elementos não estão presentes, a própria existência da comunidade pode ser afetada. Ademais, a confiança é considerada como um aspecto fundamental, principalmente para aquelas pessoas envolvidas em ações do bem comum.

"Se não tivesse confiança não teria cooperação (Entrevistado 2)".

Refletindo o relato do entrevistado pode-se associar a perspectiva apontada por Putnam (1996), em que considera a confiança como sendo a chave para a cooperação. Nesse sentido, a pesquisa identificou que os entrevistados confiam uns nos outros ao compartilhar equipamentos, realizar troca de trabalho, além de outras ações para o bem comum. A parábola de David Hume, citada por Putnam, no qual um agricultor não ajuda ao outro por falta de confiança, não se aplica a comunidade pesquisada, considerando que os entrevistados disseram haver confiança entre os membros da comunidade.

Entre os elementos abordados, a solidariedade também pode ser evidenciada na comunidade estudada, conforme evidencia o relato.

"Teve uma ação entre amigos recentemente, que moveu a comunidade e até outras comunidades, é muito importante saber que a comunidade está empenhada em ajudar e ser solidário (Entrevistado 2)". 
A ação arrecadou fundos para o tratamento de câncer de uma pessoa da comunidade. Neste sentido, observa-se a importância dos laços familiares e de amizade no contexto das comunidades. Outro exemplo de solidariedade citado pelos entrevistados foi o funeral.

"Tem lugares que vai poucas pessoas, aqui quando morre alguma pessoa toda a comunidade participa da melhor maneira possível (Entrevistado 1)".

Neste contexto, observa-se que práticas de solidariedade são constantemente realizadas no espaço dessa comunidade, podendo-se ainda aplicar o conceito de reciprocidade generalizada descrito por Putnam (1996), conceito esse que está intimamente relacionado a cooperação e a confiança. Para o autor, nas comunidades em que a reciprocidade é obedecida, os problemas da ação coletiva são mais facilmente resolvidos, características que podem ser visualizadas na comunidade pesquisada.

No que se refere a inserção das TICs no meio rural, a pesquisa verificou que todos os entrevistados têm acesso e utilizam internet, TV, rádio, telefone celular e computador, o que demonstra a importância das TICs no local de estudo. Thornton (2003) considera que as novas tecnologias permitem que as pessoas estejam em todos os lugares e em tempo real, ultrapassando as barreiras de espaço e tempo. A medida em que ocorre a inserção dessas tecnologias no meio rural, uma nova configuração da rotina se estabelece, gerando novas formas de aquisição de informações e relações entre os atores (FELIPPI; DEPONTI; DORNELLES, 2017).

"Repassa as informações pelo celular, pelo WhatsApp, é mais prático, rápido. Não precisa nem sair de casa (Entrevistado 4)".

Nesta perspectiva, observa-se que as TICs proporcionaram múltiplas facilidades, criando inúmeros laços fracos, os quais são vitais para a interação das pessoas na sociedade moderna, como afirma Granovetter (1983). Para o autor, aquele indivíduo que se relaciona com poucos laços fracos, consequentemente ficará privado de informações distantes do seu sistema social. Esse isolamento faz com que a pessoa fique limitada as opiniões e conhecimentos de seus amigos.

Assim, a internet pode ser considerada uma fonte de informações para além das interações habituais dos indivíduos. Adicionalmente, o mesmo autor aponta que caso as comunidades concentrassem suas relações em laços fortes, as informações, conhecimentos ficariam limitados aos pequenos grupos, ou seja, a restrição de informações impediria o desenvolvimento dos próprios membros do grupo. Assim, o autor considera que os laços fracos em que estamos vinculados nos possibilitam ter acesso a diferentes informações e promovem o desenvolvimento das comunidades por meio dos atores sociais.

"Hoje se torna mais fácil, você não precisa ir de casa em casa, você manda um WhatsApp, ou dá uma ligada, a informação chega mais rápido (Entrevistado 3)".

"Ela está auxiliando, trouxe benefícios, para a comunidade é muito mais prático pra se comunicar, avisar alguém (Entrevistado 1)". 
Quando questionado se as Tecnologias de Informação e Comunicação interferem nas relações sociais, é importante destacar que todos os participantes disseram que elas interferem. Um dos entrevistados disse que a tecnologia ajuda muito na comunicação, pois muitas vezes evita a locomoção, no entanto, atrapalha a relação familiar.

\begin{abstract}
"Não é como antigamente que a gente olhava olho no olho. [...] Hoje tem que chamar um no quarto que está na internet, outro que está no vídeo game, outro que está no celular, outro que está na televisão, então é um pouco difícil. Antigamente não tinha isso, a gente sentava numa roda e tratava das coisas. Esses dias, até tava brincando, a minha mulher para falar com o meu filho no quarto tava com o WhatsApp mandando mensagem, porque ele não saía do quarto, então isso influencia na parte negativa (Entrevistado 3)".
\end{abstract}

"O celular ajuda aproximar os que estão longe, mas distância quem está perto (Entrevistado 2)”.

Nesta perspectiva, observa-se que na contemporaneidade as TICs inseremse nas relações sociais e geram novas redes socais, que por conseguinte criam novos comportamentos entre os atores sociais. Ademais, podem ser consideradas instrumentos de informação ou desinformação, confiança ou má fé, afetando diretamente as relações sociais.

Diante do exposto, a pesquisa revelou que principalmente o celular tem auxiliado na troca de informações na comunidade e também possibilitado a comunicação com atores sociais para além dos limites da comunidade local.

Neste cenário, a internet exerce um papel fundamental que pode colaborar de diversas formas com o desenvolvimento local, além de auxiliar na implantação de novas iniciativas de produção e evitar o êxodo rural. Ao mesmo tempo, a falta dessas tecnologias pode aumentar ainda mais a desigualdade entre os territórios.

Embora as TICs possibilitem múltiplas maneiras de acesso à informação, elas também podem gerar maior desconfiança. Entre os entrevistados foi mencionada a questão da desconfiança, relacionada principalmente à internet. Um dos participantes disse que nem todas as informações que chegam são verdadeiras, ou seja, trazem uma série de dúvidas.

"A gente não sabe quem está do outro lado, você está conversando com alguém mas, será que é ou não é? (Entrevistado 2)".

Outro apontamento mencionado pelo entrevistado 4 está relacionado com os frequentes trotes por telefone que também causam uma sensação de desconfiança. Neste contexto, percebe-se que elementos como a má-fé e o oportunismo, são intensificados a partir das novas tecnologias, como o celular e a internet.

Diante disso, observa-se que as Tecnologias de Informação e Comunicação trazem inúmeros riscos e implicações para as relações sociais, neste caso, ao meio rural. Logo, ao mesmo tempo em que oferecem possibilidades de comunicação, troca de informações, agilidade, também causam afastamento e desconfiança. À medida em que as redes sociais eletrônicas unificam o espaço e tempo das pessoas, também podem desvirtuar o objetivo do grupo social tornando-os reféns de 
um consenso que pode ser manipulado. Dessa forma, o debate pode ser direcionado à outros focos o que tende a desmobilizar e desmotivar a confiança.

\section{CONSIDERAÇÕES FINAIS}

O presente estudo situa-se nas discussões sobre a influência das Tecnologias de Informação e Comunicação nas relações sociais. Nesse sentido, o objetivo foi verificar se essas tecnologias fortalecem ou tornam frágeis os laços de confiança, solidariedade, cooperação, no meio rural.

A pesquisa mostrou que as TICs transformaram as formas de relações sociais, principalmente facilitando a troca de informações. Observou-se que, elementos como confiança, solidariedade e cooperação continuam sendo praticados na comunidade estudada, por meio de mutirões, rezas, campanhas entre outras ações. No entanto, os participantes da pesquisa disseram que antigamente esses elementos "cívicos" estavam presentes de maneira mais forte na comunidade.

Adicionalmente, percebeu-se que os grupos formados na comunidade, como o clube de mães, idosos, tornam-se um instrumento importante para reivindicar os objetivos em comum, o que seria menos possível se cada um agisse por conta própria. Neste sentido, as TICs podem ser consideradas importantes no que se refere a organização e mobilização dos atores sociais.

Neste cenário de transformações, inclusive nas relações sociais, é preciso ter cuidado para que as novas tecnologias não tornem frágeis os laços de cooperação, confiança, solidariedade, pois são esses elementos que sustentam as comunidades.

$\mathrm{Na}$ contemporaneidade, percebe-se o gigantesco poder de mobilização por meio da Internet, no entanto, é um instrumento de dois gumes, ao mesmo tempo pode informar como também desinformar e replicar rapidamente notícias falsas. Neste contexto, essa tecnologia torna-se um instrumento de insegurança, má fé e pode gerar problemas graves nas relações sociais, afetando principalmente os laços de confiança entre os atores sociais.

\section{REFERÊNCIAS}

ABRAMOVAY, R. O capital social dos territórios: repensando o desenvolvimento rural. Economia Aplicada, v. 4, n. 2, p. 379-397, 2000.

ALBAGLI, S. Território e Territorialidade. In: LAGES, V.; BRAGA, C.; MORELLI, G. (Orgs.). Territórios em movimento: cultura e identidade como estratégia de inserção competitiva. Rio de Janeiro: SEBRAE, 2004.

AMARAL FILHO, J. A endogeneização no desenvolvimento econômico regional e local. Planejamento e Políticas Públicas, n. 23, p. 261-286, 2001.

ANDRADE, B. O.; SANTOS, M. S. T. Extensão rural e cibercultura: o facebook como ferramenta de promoção da política nacional de assistência técnica e extensão rural. Extensão Rural, Santa Maria, v. 22, n. 3, p. 29-47, 2015. Disponível em: https://periodicos.ufsm.br/extensaorural/article/view/10014/pdf. Acesso em: 23 jun. 2019.

BLANCO ROMERO, A.; CÀNOVES VALIENTE, G. Las tecnologías de la información y la comunicación en el desarrollo del turismo rural. Documents d'Anàlisi Geogràfica, n. 46, p.105-117, 2005. 
CASTELLS, M. A sociedade em rede. A era da informação: economia, sociedade e cultura. São Paulo: Paz e Terra, 2010.

CONCEIÇÃO, A. F. "Quem está online?" - um estudo de caso sobre o uso e apropriação da internet por agricultores familiares de Estrela/RS. Dissertação (Mestrado em Extensão Rural), Universidade Federal de Santa Maria, Santa Maria, 2012.

FELIPPI, Â. C. T; DEPONTI, C. M; DORNELLES, M. TICs na Agricultura Familiar: os usos e as apropriações em regiões do Sul do Brasil. Revista Brasileira de Gestão e Desenvolvimento Regional, v. 13, n. 1, p. 3-31, 2017.

GIL, A. C. Métodos e técnicas de pesquisa social. $6^{\underline{a}}$ ed. $3^{\underline{a}}$ reimpr., São Paulo: Atlas, 2010.

GRANOVETTER, M. The strength of weak ties. In: American Journal of Sociology, University Chicago Press, Chicago, v. 78, n 6, 1973.

GRANOVETTER, M. The strength of weak ties: a network theory revisited. Sociological Theory, 1983.

GRANOVETTER, M. Ação econômica e estrutura social: o problema da imersão. Sociologia Econômica, v. 6, n. 1, 2007.

INSTITUTO BRASILEIRO DE GEOGRAFIA E ESTATÍSTICA (IBGE). Agência IBGE notícias. Censo Agro 2017: resultados preliminares mostram queda de 2,0\% no número de estabelecimentos e alta de $5 \%$ na área total. Disponível em: https://agenciadenoticias.ibge.gov.br/agencia-sala-de-imprensa/2013-agencia-denoticias/releases/21905-censo-agro-2017-resultados-preliminares-mostram-quedade-2-0-no-numero-de-estabelecimentos-e-alta-de-5-na-area-total.html. Acesso em: 29 jul. 2018.

INSTITUTO BRASILEIRO DE GEOGRAFIA E ESTATÍSTICA (IBGE). Censo Demográfico 2010. Sinopse do Censo Demográfico 2010. Disponível em: https://censo2010.ibge.gov.br/sinopse/index.php?uf=42\&dados=29. Acesso em: 13 nov. 2018.

INSTITUTO BRASILEIRO DE GEOGRAFIA E ESTATÍSTICA (IBGE). Censo Agropecuário 2006. Número dos estabelecimentos agropecuários com agricultura familiar e não familiar. Disponível em: https://sidra.ibge.gov.br/Tabela/1966\#resultado. Acesso em: 31 out. 2018.

MINAYO, M. C. S. (Org.). Pesquisa social. Teoria, método e criatividade. Petrópolis: Editora Vozes, 2009.

OLIVEIRA, M. M. Como fazer pesquisa qualitativa. 4 ed. Petrópolis: Vozes, 2012.

POLANYI, K. A grande transformação: as origens da nossa época. Rio de Janeiro: Campus, 1980. 
PUTNAM, R. D. Comunidade e Democracia: a experiência da Itália moderna. Rio de Janeiro: Fundação Getúlio Vargas, 1996.

RICHARDSON, R. J. Pesquisa Social: métodos e técnicas. Colaboradores José Augusto de Souza Peres et al. 3.ed. 16ª reimpr. São Paulo: Atlas, 2015.

SANTOS, A. Q. Inclusão digital e desenvolvimento local no Brasil. In: CONGRESSO INTERNACIONAL DEL CLAD SOBRE LA REFORMA DEL ESTADO Y DE LA ADMINISTRACIÓN PÚBLICA, VIII, 2003. Anais... Caracas, 2003, p. 1-13.

SCHAFF, A. A sociedade informática: as consequências sociais da segunda revolução industrial. São Paulo: UNESP, 1995.

THORNTON, R. El agricultor, Internet y las barreras a su adopción. In: THORNTON, R.; CIMADEVILLA, G. La extensión rural en debate. Buenos Aires: INTA, 2003.

VIERO, V. C.; SILVEIRA, A.C. M. Apropriação de tecnologias de informação e comunicação no meio rural brasileiro. Cadernos de Ciência \& Tecnologia, v. 28, n. 1, p. 257-277, 2011. 